\title{
Poly(Ethylene Glycol) Functionalized Graphene Oxide in Tissue Engineering: A Review on Recent Advances
}

This article was published in the following Dove Press journal: International Journal of Nanomedicine

\section{Santanu Ghosh \\ Kaushik Chatterjee (D)}

Department of Materials Engineering, Indian Institute of Science, Bangalore, India
Correspondence: Kaushik Chatterjee Tel +9l-80-22933408

Email kchatterjee@iisc.ac.in

\begin{abstract}
Owing to the unique physical, chemical, mechanical and electrical properties, graphene and its derivatives have been extensively researched for diverse biomedical applications including in tissue engineering since the past decade. Tunable chemical functionalities of graphene oxide (GO), a graphene derivative, allow easy surface functionalization. Functionalization of GO with poly(ethylene glycol) (PEG) (PEG-GO) has received significant attention as it offers superior solubility, stability, and biocompatibility. Besides being an attractive candidate for drug delivery, PEG-GO can aid in the attachment, proliferation, and differentiation of stem cells, thereby augmenting tissue engineering. PEG-GO has shown excellent antibacterial efficacy, which could be an added advantage to minimize implantassociated infections. This review describes the synthesis techniques, properties, and biological potential of PEG-GO towards mammalian and bacterial cells. Studies wherein these nanomaterials have been explored for engineering various tissues are reviewed along with future opportunities in this field.
\end{abstract}

Keywords: graphene, graphene oxide, PEG, poly(ethylene glycol), nanomaterials, tissue engineering

\section{Introduction}

Since the report of Novoselov et $\mathrm{al}^{1}$ on the first two-dimensional (2D) carbonaceous material, graphene has attracted enormous interest in the field of nanotechnology owing to its unique mechanical, thermal, and optical properties. ${ }^{2,3}$ The single layer of graphene consists of $\mathrm{sp}^{2}$ hybridized carbon atoms connected to each other forming a honeycomb lattice structure. ${ }^{4}$ Several top-down and bottom-up techniques have been successfully employed to prepare graphene and its derivatives. These methods broadly involve chemical exfoliation, mechanical exfoliation, chemical-vapor deposition, and epitaxial growth. ${ }^{5}$ Different synthesis methods may yield different derivatives of graphene where the primary difference lies in the chemical functionalities on the nanomaterial. Chemical exfoliation is widely employed to produce graphene sheets rich in oxygen-containing functional groups and is referred to as graphene oxide (GO). Subsequent chemical/thermal treatment of GO results in reduced graphene oxide (rGO) with fewer such groups. ${ }^{6}$

Owing to the ultra-high surface area, tunable opto-electronic properties, and easy functionalization, graphene and its derivatives such as GO and rGO have been extensively explored in biomedical research for the last decade including but not limited to drug delivery, gene delivery, protein delivery, bio-imaging, photothermal 
therapy, and tissue engineering, etc. ${ }^{7,8}$ However, clinical translation of graphene-based technologies has been slow due to challenges such as non-specific adsorption of proteins, poor stability in biological fluids, and cytotoxicity. To overcome these bottlenecks, researchers have exploring different routes for functionalizing GO. A popular and promising strategy has been the functionalization with poly (ethylene glycol) (PEG-GO) through covalent bonding or non-covalent interactions, which imparts remarkably high aqueous stability as well as enhanced biocompatibility.

Unlike GO, PEG-GO remains highly dispersed in serumcontaining solutions, ${ }^{9}$ which enables it to serve as a superior carrier for hydrophobic drugs. Xu et $\mathrm{al}^{10}$ delivered paclitaxel, a hydrophobic anticancer drug using PEG-GO, which was stable as well as biocompatible in physiological fluids. Liu et $\mathrm{al}^{11}$ observed that although GO was soluble in water, it aggregated in aqueous solutions rich in salts and proteins due to electrostatic interactions or non-specific protein binding. So, covalently conjugation of star-shaped PEG-amine with GO enhanced aqueous stability rendering it suitable for delivering hydrophobic molecules. Kazempour et $\mathrm{al}^{12}$ used PEG-GO to successfully load another anticancer drug doxorubicin. The nanohybrid exhibited $\mathrm{pH}$-dependent drug release with superior cytocompatibility than the unmodified GO. Yang et $\mathrm{al}^{13}$ studied the long-term biodistribution, pharmacokinetics and the toxicity of PEGylated GO in vivo. They have observed no obvious toxicity at a dose of $20 \mathrm{mg} / \mathrm{kg}$ in Balb/c mice using a combination of hematology, histology, and biochemical analysis of blood. The nanoparticles were cleared through renal and fecal excretion. PEG-GO was also investigated for photodynamic therapy. Tian et $\mathrm{al}^{14}$ developed a nanoconstruct using PEG and GO loaded with a photosensitizer Chlorin e6 (Ce6) through supramolecular $\pi$ - $\pi$ stacking. They utilized the photothermal property of graphene to initiate the delivery of Ce6 by local heating with a low power near-infrared (NIR) laser. Zhang et $\mathrm{al}^{15}$ further demonstrated the potential of dual therapy by synergistically using photothermal therapy and delivery of chemotherapeutic drug using PEG-GO.

GO has emerged as a promising candidate material for tissue engineering. Tissue engineering is defined as

an interdisciplinary field that applies the principles of engineering and the life sciences toward the development of biological substitutes that restore, maintain, or improve tissue function. ${ }^{16}$

Clinical translation of engineered tissues is being vigorously pursued to develop therapies to overcome the lack of available donor organs and tissues, and the limitations of transplants. However, several bottlenecks have hindered clinical successes in this field. ${ }^{17,18}$ An essential component of tissue engineering is the scaffold to allow the cells to home in. It typically mimics the extracellular matrix (ECM) for maximizing tissue regeneration by providing physicochemical and biomolecular cues to the cells. ${ }^{19}$ Graphene and its derivatives are being explored for preparing scaffolds for bone, ${ }^{20}$ cartilages, $^{21}$ cardiac $^{22}$ and neural tissues, ${ }^{23}$ among others. As discussed above, PEG modification of GO can markedly enhance its biodistribution and stability as well as biocompatibility. Consequently, PEGGO in tissue scaffolds can improve functionality while imparting unique attributes for regeneration.

Several authors have reviewed the potential of graphene in biomedicine ${ }^{24,25}$ and specifically in tissue engineering. ${ }^{6,26}$ However, a detailed review on using PEG-GO in tissue engineering is not available and is the focus of this review. This article describes different techniques for preparing PEG-GO, its physico-chemical characteristics, its cellular interactions and biological responses, and its application in engineering different types of tissues (Figure 1).

\section{Synthesis of GO}

Chemical exfoliation is the most popular strategy to prepare GO. The synthesis of GO from graphite involves two steps. In the first step, oxidation of graphite results in the incorporation of different oxygen-rich functionalities such as carbonyl $(-\mathrm{C}=\mathrm{O})$, carboxyl $(-\mathrm{COOH})$, hydroxyl $(-\mathrm{OH})$, and epoxy (-C-O-C-) groups, on the basal planes as well as on the edges. In the second step, the oxidized 3D graphite is exfoliated in specific solvents by sonication to yield atomically thin $2 \mathrm{D}$ sheets of GO.

Various techniques can yield GO but they differ on the choice of the oxidizing agent and the process parameters including the methods reported by Brodie, ${ }^{27}$ Staudenmaier, ${ }^{28}$ and Hummers, ${ }^{29}$ and subsequently, modified Hummers method. ${ }^{30}$ In 1859, Brodie synthesized graphite oxide by adding graphite into an oxidation medium containing potassium chlorate and nitric acid. Staudenmaier modified Brodie's method using aliquots of potassium chlorate during the reaction. To enhance the oxidation, Staudenmaier additionally used sulfuric acid, which could be performed within a single reaction vessel. Subsequently, in 1958, Hummers proposed the use of sodium nitrate, potassium permanganate, and concentrated sulfuric acid. However, the major disadvantage associated with the Hummers' method was the formation of dimanganese heptaoxide by the reaction of potassium permanganate and concentrated sulfuric acid, which can cause an 


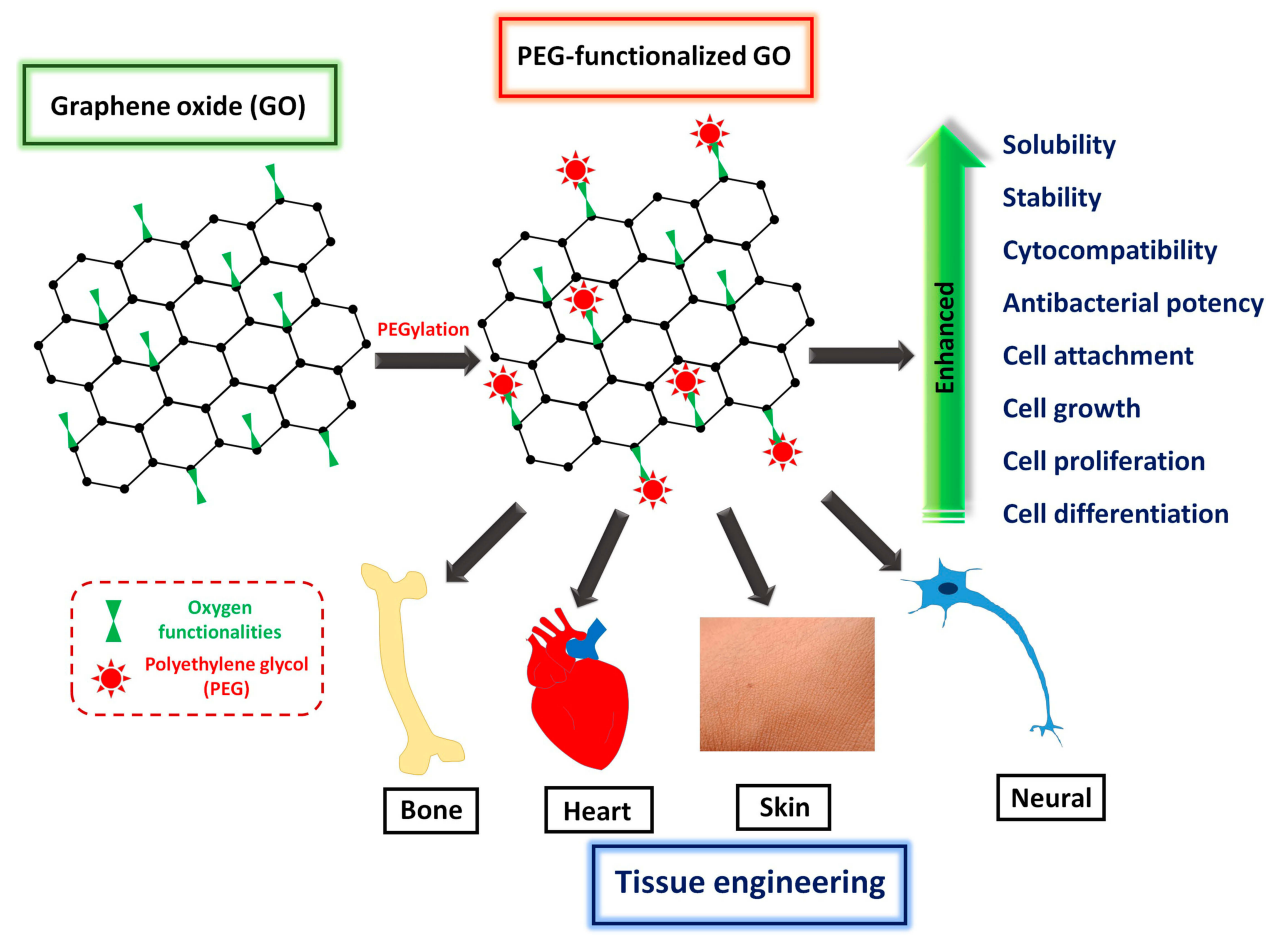

Figure I Schematic representation of the enhanced properties and subsequent tissue engineering applications of PEG-functionalized GO.

explosion if the reaction temperature exceeds $55^{\circ} \mathrm{C} .^{31}$ Marcano et $\mathrm{al}^{30}$ proposed the use of more potassium permanganate in a mixture of sulfuric acid and phosphoric acid (9:1) for higher yield of hydrophilic oxidized graphene compared to Hummers' method.

\section{Synthesis of PEG Functionalized GO (PEG-GO)}

PEG Functionalization of GO can be achieved by covalent or non-covalent interactions. Different processes to synthesize PEG-GO are discussed in this section.

\section{Synthesis of PEG-GO Through Covalent Interactions}

As GO contains oxygen-bearing functionalities, it can be easily functionalized through covalent interactions, that is, esterification, ${ }^{32}$ amidation, ${ }^{33}$ amination, ${ }^{34}$ or urethane linkage. ${ }^{35}$ Amidation is the most popular method and is achieved through carbodiimide coupling (Figure 2A). Liu et $\mathrm{al}^{11}$ sonicated GO to prepare small sheets and conjugated six-armed PEG-amine stars to the carboxylic acid group of GO via carbodiimide-catalyzed amide formation. Attenuated total reflection infrared spectroscopy revealed peaks at $2850 \mathrm{~cm}^{-1}$ and $1100 \mathrm{~cm}^{-1}$ for the $\mathrm{C}-\mathrm{H}$ and $\mathrm{C}-\mathrm{O}$ bonds, respectively, confirming the presence of PEG
(Figure 2B). $\mathrm{Xu}$ et $\mathrm{al}^{10}$ functionalized $\mathrm{GO}$ with six-armed PEG through facile amidation under mild reaction conditions. Fourier-transform infrared analysis and elemental analysis (Figure 2C) of the PEG-GO indicated reduced oxygen content and the presence of nitrogen after PEG functionalization. In lieu of carbodiimide coupling, Kazempour et $\mathrm{al}^{12}$ modified GO with acyl chloride to conjugate PEG-4000 and confirmed using X-ray diffraction (Figure 2D). The peak at $2 \theta=11.59^{\circ}$ due to the 002 diffractions indicated successful formation of GO with a d-spacing of $7.629 \mathrm{~nm}$, whereas for GO-PEG 4000, two peaks at $2 \theta=5.26^{\circ}$ and $25.33^{\circ}$ indicated increased d-spacing value of $16.7872 \mathrm{~nm}$ of $\mathrm{GO}$ after functionalization, and the successful conjugation of PEG, respectively.

Zhang et $\mathrm{al}^{36}$ conjugated PEG molecules of different molecular weight to GO through ester linkage and noted good dispersion in both protic and non-protic solvents along with improved thermal stability. Transmission electron microscopy (TEM) revealed that GO-PEG400 nanosheets were crumpled and wrinkled on the edges due to the strong interactions between PEG and GO. PEG-GO significantly increased the thermal stability of PEG4000. Liu et $\mathrm{al}^{11}$ demonstrated that covalently conjugated PEG-GO was stably dispersed in water, phosphate-buffered saline (PBS), complete culture medium and serum whereas, GO settled down partially in PBS and completely in both culture medium and serum (Figure 2E). These results underscore the 
A

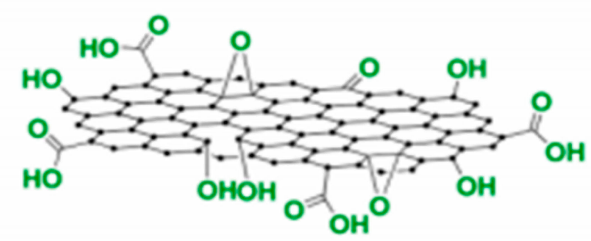

Graphene Oxide

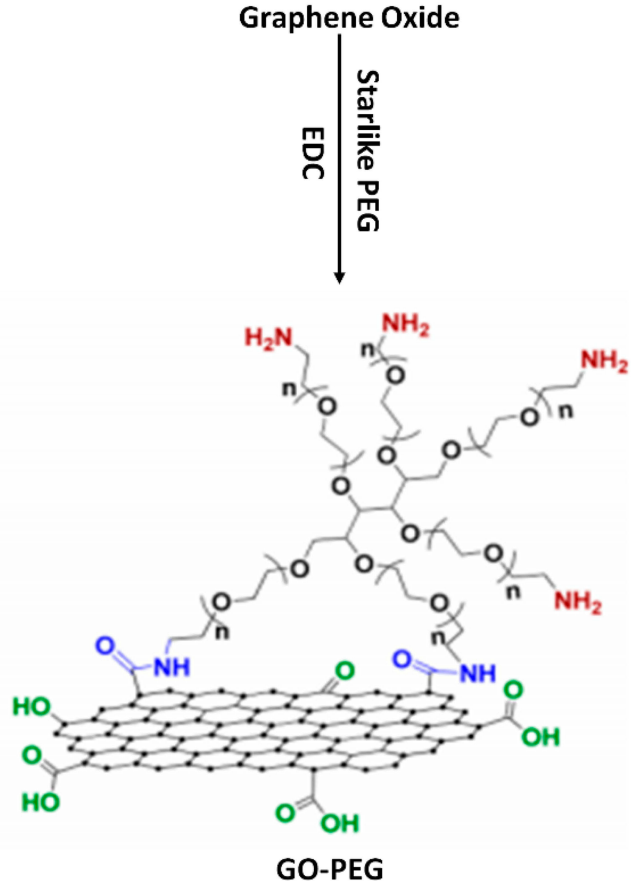

B

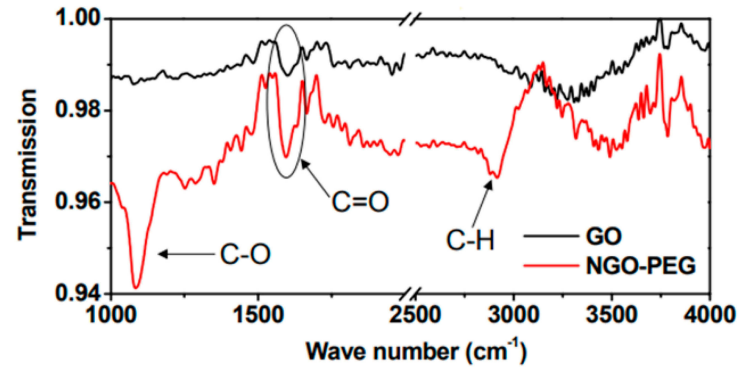

C

\begin{tabular}{lcccc}
\multicolumn{1}{c}{ sample } & $\mathrm{C} \mathrm{(wt} \mathrm{\% )}$ & $\mathrm{H}(\mathrm{wt} \%)$ & $\mathrm{O}(\mathrm{wt} \%)$ & $\mathrm{N}(\mathrm{wt} \%)$ \\
graphite powder & 97.8 & 0.6 & 1.6 & 0 \\
GO & 47.4 & 3.4 & 49.2 & 0 \\
GO-PEG & 53.9 & 7.7 & 36.5 & 1.9
\end{tabular}

D

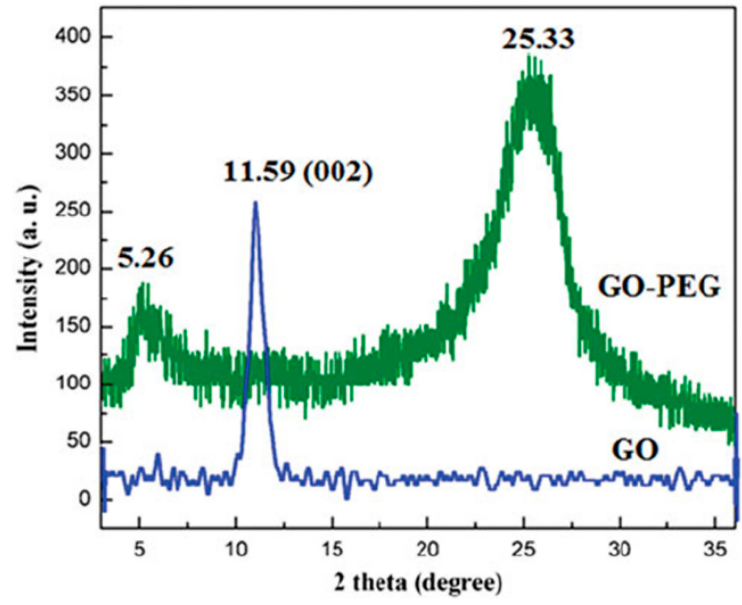

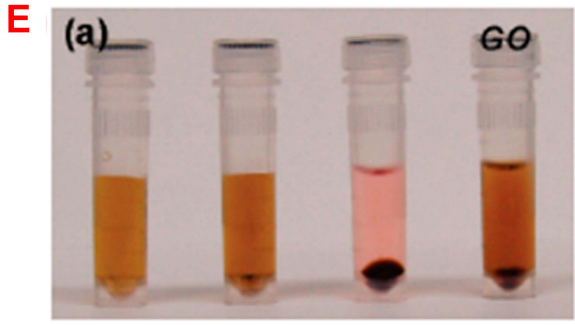
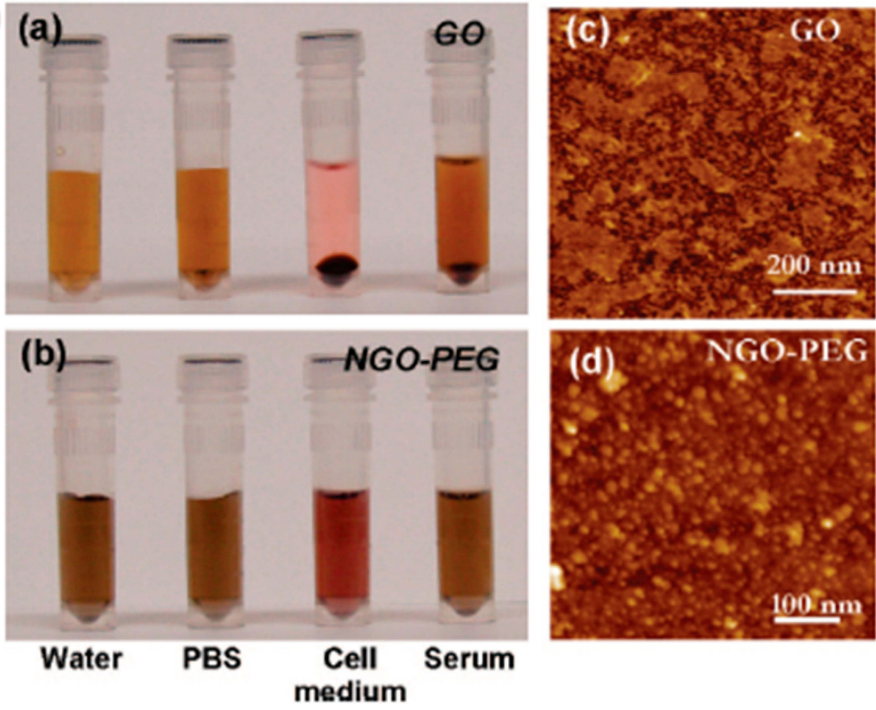

Figure 2 (A) Schematic representation of PEG functionalized GO synthesis through carboiimide formation. Reprinted with permission from Xu Z, Wang S, Li Y, Wang M, Shi P, Huang X. Covalent functionalization of grapheneoxide with biocompatible poly (ethylene glycol) for delivery of paclitaxel. ACS Appl Materlnterfaces. 20I4;6(I9): I7268-I7276. Copyright 20I4 American Chemical Society. ${ }^{10}$ (B) Comparisons of GO and PEG functionalized GO through ATR-IR analysis. Reprinted with permission from Liu Z, Robinson JT, Sun X, Dai H. PEGylated nanographene oxide for delivery ofwater-insoluble cancer drugs. J Am Chem Soc. 2008;130(33): 10876- I0877. Copyright 2008 American Chemical Society. "I (C) Elemental analysis of graphite powder, GO and GO-PEG showed presence of nitrogen in case of GO-PEG. Reprinted with permission from Xu Z, Wang S, Li Y, Wang M, Shi P, Huang X. Covalent functionalization of grapheneoxide with biocompatible poly (ethylene glycol) for delivery of paclitaxel. ACS Appl MaterInterfaces. 20I4;6(I9):I7268-I7276. Copyright 20I4 American Chemical Society. ${ }^{10}$ (D) X-ray diffraction data of GO (blue line) and GO-PEG 4000 (green line). Reproduced from Kazempour M, Namazi H, Akbarzadeh A, Kabiri R. Synthesis and characterization of PEG-functionalized graphene oxide as an effective $\mathrm{pH}$-sensitive drug carrier. Artif Cells, Nanomed, Biotechnol. 2019;47(I):90-94. Creative Commons license and disclaimer available from: http://creativecommons.org/licenses/by/4.0/legalcode. ${ }^{12}$ (E) Stability of (a) GO and (b) PEGylated nanoscale GO (NGO-PEG) in different solutions i.e. PBS and cell medium after centrifugation at $10000 \mathrm{~g}$ for $5 \mathrm{~min}$. GO precipitated slightly in PBS and completely in cell medium and serum (a). NGO-PEG was found to be stable in all solutions (b); atomic force microscopic (AFM) images of (c) GO and (d) NGO-PEG. Reprinted with permission from Liu Z, Robinson JT, Sun X, Dai H. PEGylated nanographene oxide for delivery ofwater-insoluble cancer drugs. J Am Chem Soc. 2008;130(33):I0876-10877.Copyright 2008 American Chemical Society. " 

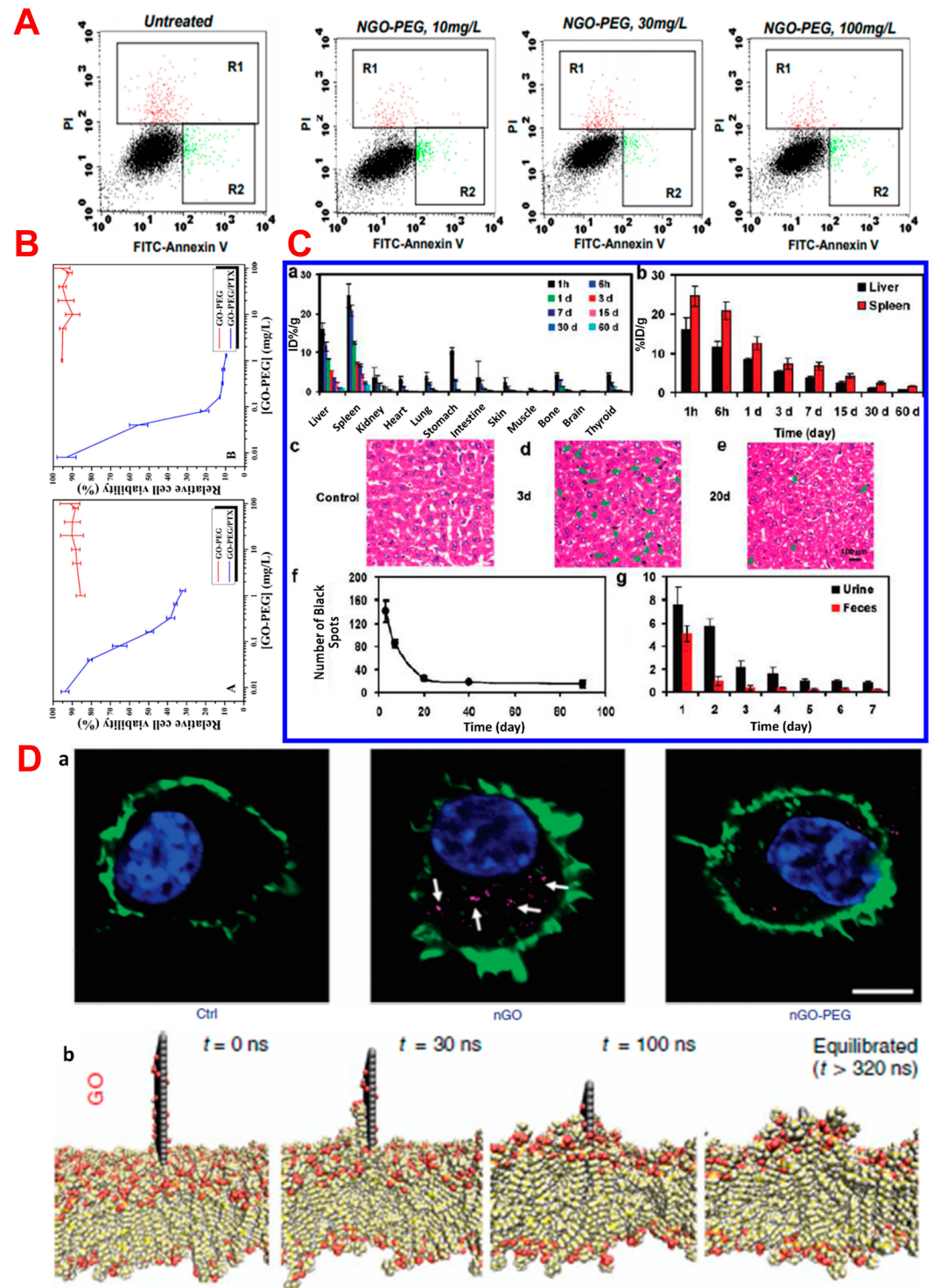

Equilibrated
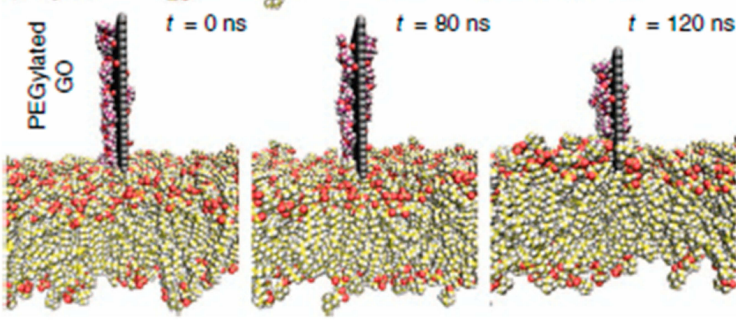

$=120 \mathrm{~ns}$

$(t>320 \mathrm{~ns})$
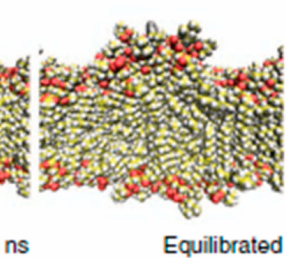

$t>320 \mathrm{~ns}$

Figure 3 (A) Apoptosis assay was done by FACS. MCF-7 cells treated with different concentrations of NGO-PEG. RI (red) represent region of dead cells and R2 (green) represent the regions of apoptotic cells. Reprinted with permission from Liu Z, Robinson JT, Sun X, Dai H. PEGylated nanographene oxide for delivery of water-insoluble cancer drugs. J Am Chem Soc. 2008; 130(33): 10876-10877.Copyright 2008 American Chemical Society. " (B) Cell viability of GO-PEG (red line) and GO-PEG/PTX against A549 (A) and MCF-7 (B) after 72 h of incubation. Reprinted with permission from Xu Z, Wang S, Li Y, Wang M, Shi P, Huang X. Covalent functionalization of grapheneoxide with biocompatible poly (ethylene glycol) for delivery of paclitaxel. ACS Appl MaterInterfaces. 2014;6(19): 1 7268-76. Copyright 2014 American Chemical Society. ${ }^{10}$ (C) In vivo biodistribution and clearance data of NGS-PEG in female Balb/cmice. (a) Time-dependent biodistributionin major organs of I25I-NGS-PEG. (b) presence of I25I-NGS-PEG in the liver and spleen over different time points. (c-e) Haemotoxylin and Eosin (H\&E) stained liver sections from the untreated control mice(c) and NGS-PEG treated mice at day 3 (d) and day 20 (e) of post injection. (f) Statistic of the numbers of black spot in liver sections at various time point after NGS-PEG administration. Each data point was the average of 5 images under a $20 X$ objective. (g) the levels of ${ }^{125}$ I-NGS-PEG in urine and faeces in the first week of post injection. Excretions of mice were collected by metabolism cages. Standard deviations of 4-5 mice per group were taken for the error bar. Reprinted with permission from Yang K, Wan J, Zhang S, Zhang Y, Lee ST, Liu Z. In vivo pharmacokinetics, long-term biodistribution, and toxicology of PEGylated graphene in mice. ACS Nano. 20I I;5 (I):516-22. Copyright 20II American Chemical Society ${ }^{13}$ and (D) Internalization of $n G O, n G O-P E G$ by peritoneal macrophages (white arrow indicated the $n G O$ as purple dots) (a), Snapshots of membrane insertion processes of GO and PEGylated GO during stimulation, (carbons of GO represented in grey color and covalently linked PEG chains are in purple color) (b). Reproduced from Luo N, Weber JK, Wang S, et al. PEGylated graphene oxide elicits strong immunological responses despite surfacepassivation. Nat Commun. 20 I7;8(I):I. Creative Commons license and disclaimer available from: http://creativecommons.org/licenses/by/4.0/legalcode. ${ }^{47}$ 
role of PEG functionalization for enhanced stability in biological fluids.

\section{Synthesis of PEG-GO Through Non-Covalent Interactions}

Covalent attachment of small molecules or polymers minimizes aggregation thereby imparting stability in solution, as discussed above. However, it alters the electronic properties of graphene, which may be eliminated through non-covalent surface functionalization. ${ }^{37}$ Park et $\mathrm{al}^{37}$ compared the solubility of GO functionalized with PEG through covalent and non-covalent interactions. Subsequent reduction of GO covalently functionalized with $P E G$ resulted in precipitation of graphite-like material. Interestingly, when PEG molecules with the amine functionalization at both the ends were attached non-covalently with GO, subsequent reduction resulted in a stable solution without precipitation ithat was stable for as long as six months. They proposed that the non-covalent interactions were achieved through the formation of hydrogen bonds or electrostatic interactions of the carboxylic acid groups on GO with the terminal amines in PEG.

Zhang et $\mathrm{al}^{38}$ demonstrated good mechanical properties of the graphene film through non-covalent $\pi-\pi$ interactions with homo-telechelic functionalized PEG. First, they tailored PEG with $\pi$-orbital-rich groups such as pyrene, di-pyrene, and phenyl via esterification to enhance the interaction of PEG with rGO. They found that $\pi-\pi$ interactions between graphene and $\pi$-orbital-rich groups attached with PEG endowed enhanced tensile strength and tunable electrical conductivity. The enhanced strength was due to the presence of telechelic group such as pyrene attached onto the surface of graphene, whereas the flexible PEG chains allowed the interconnection between the nanocomponents. They concluded that the mixture of non-conductive polymer and conductive graphene endowed tunable electrical conductivity to the final product. The terminal phenyl groups imparted the most favored conductivity. ${ }^{38}$

\section{GO and PEG-GO: Molecular Dynamic Simulations and Density Functional Theory (DFT) Calculations}

A few of studies using theoretical calculations and simulations have been reported to assess the bioactivity of GO and PEGGO. A recent review by Kumar and Parekh ${ }^{39}$ elaborately discusses the mechanisms of molecular adsorption of different proteins on various graphene-based materials (GBMs), and the resultant conformational changes in the structure of proteins and effect on cellular functions. Cell attachment and growth are related to the attachment of different serum proteins on the GBM surfaces and this molecular adsorption of protein depends on the surface chemistry of GBMs. The interaction of GBMs with serum proteins was studied by Chong et al ${ }^{40}$ using a combination of experimental studies and molecular dynamics simulations. Simulations revealed that the adsorption of the protein on the GO surface is enthalpically driven through $\pi-\pi$ stacking and the hydrophobic interactions with the aromatic residues of the proteins. They claimed that protein adsorption was dramatically enhanced for GO than to the single-walled carbon nanotubes (SWCNTs). Furthermore, protein adsorption was less on $\mathrm{rGO}$ than on $\mathrm{GO}$, as $\mathrm{rGO}$ offers less electrostatic interactions and hydrogen bonding. Baweja et $\mathrm{al}^{41}$ described that the molecular interaction of amyloid beta $(\mathrm{A} \beta)$ peptide with $\mathrm{GO}$ and $\mathrm{rGO}$ were different. Simulations revealed that unlike GO, rGO interacts with the peptide through van der Waals forces.

Mechanisms of interaction with different drugs have also been calculated using density functional theory (DFT). Vovusha et $\mathrm{al}^{42}$ recently demonstrated the binding characteristics of doxorubicin with GO and graphene. The study revealed that doxorubicin could better bind to graphene through $\pi-\pi$ stacking interactions compared to GO, which were supported by fluorescence measurements. They have also indicated that interaction of doxorubicin was stronger with $\mathrm{sp}^{2}$ regions than the $\mathrm{sp}^{3}$ regions of GO.

Aside from $\mathrm{GO}$ and $\mathrm{rGO}$, PEGylated $\mathrm{GO}$ and $\mathrm{rGO}$ have been studied through molecular dynamic simulations and DFT calculations to assess their ability as a drug carrier system. Recently, Mahdavi et $\mathrm{al}^{43}$ investigated the loading and dynamics of the anticancer drug, doxorubicin, on PEG and PEG-GO using molecular dynamic simulations. The PEG-doxorubicin solvent-accessible contact area increased with increase in the length of the PEG chain. This computational study revealed that long chains of PEG could increase the drug loading. In future, such theoretical studies could aid researchers in developing drug-eluting tissue scaffolds containing PEGylated GO.

\section{Biocompatibility of PEG-GO}

Biocompatibility is a key consideration for evaluating a material for tissue regeneration. The toxicity and compatibility of graphene and graphene derivatives have been reported extensively. In this section, we discuss about the 
PDMS

A

Day 1

Day 3

Day 7

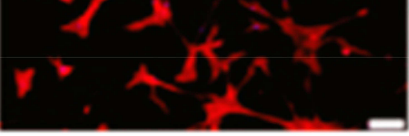

Day 10

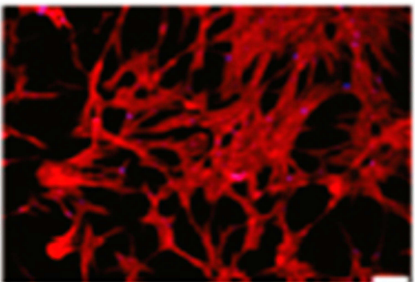

(b)
G
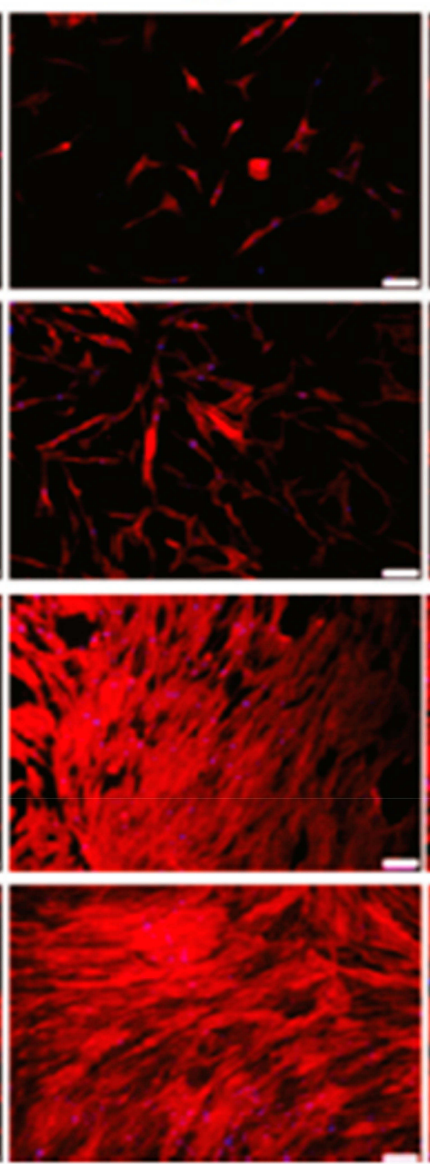

(c)

(i)

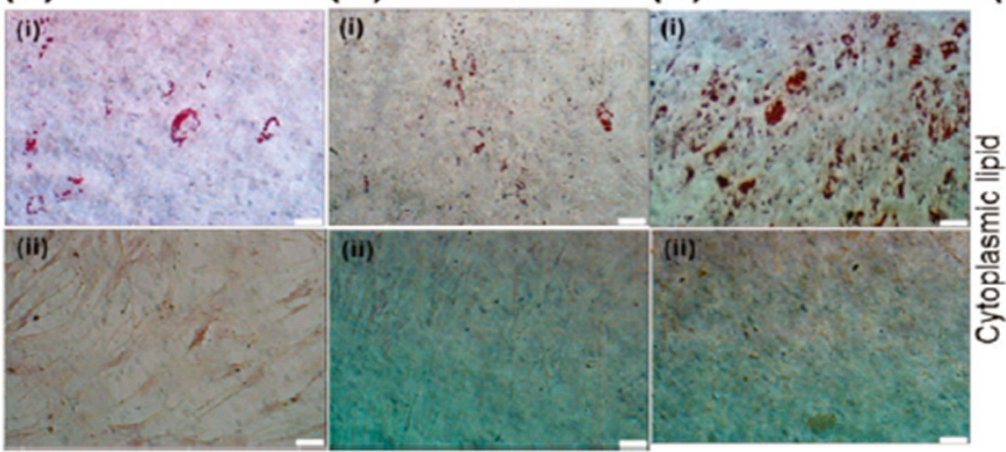

(d)
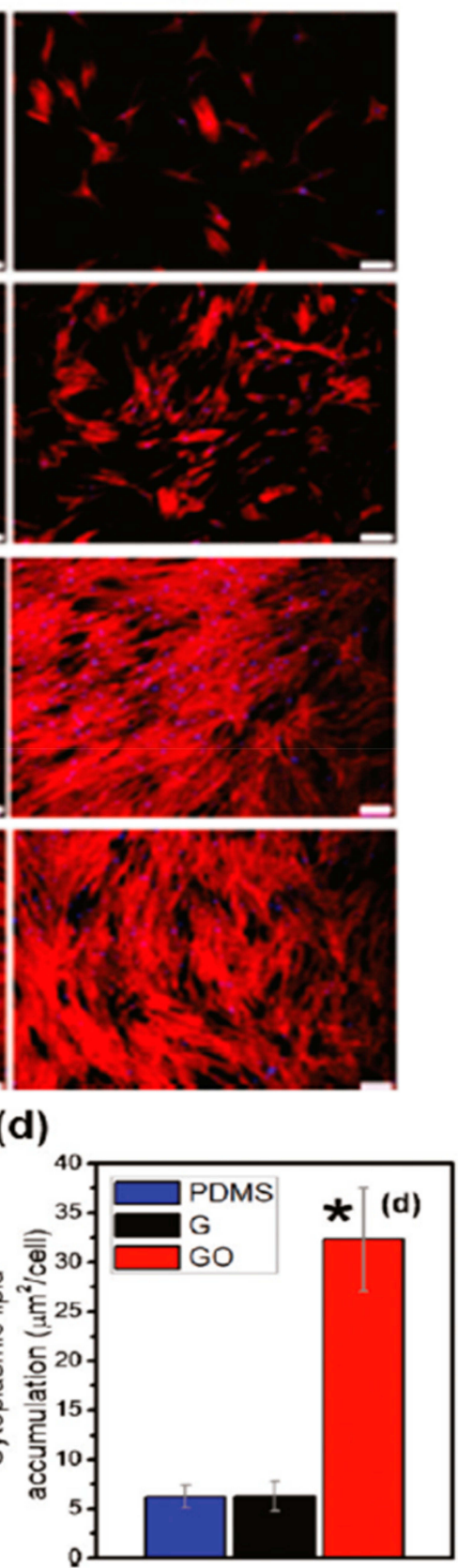

Figure 4 (A) Fluorescent images of rhodamine-phalloidin stained actin cytoskeleton of MSCs cultured on PDMS, G, and GO at day I, 3, 7, and I0. Scale bars of the images are $100 \mu \mathrm{m}$. Reprinted with permission from Lee WC, Lim CH, Shi H, et al. Origin of enhanced stem cell growth and differentiation on graphene and graphene oxide. ACS Nano. 20I I;5(9):7334-4I. Copyright 201 I American Chemical Society. ${ }^{52}$ (B) Oil Red O staining to assess cytoplasmic lipid accumulation after 14 days of (i) with and (ii) without induction on (a) PDMS, (b) G, (c) GO. Scale bars are of $50 \mu \mathrm{m}$. (d) Significantly larger amount of fat accumulation for the MSCs differentiated on GO indicated higher susceptibility for adipogenic differentiation than MSCs differentiated on PDMS (a(i)) and $\mathrm{G}(\mathrm{b}(\mathrm{i}))\left({ }^{*} \mathrm{p}<0.05 ; \mathrm{n}=4\right)$. No lipid deposition was observed for negative controls without any adipogenic induction agents. Reprinted with permission from Lee WC, Lim $\mathrm{CH}$, Shi $\mathrm{H}$, et al. Origin of enhanced stem cell growth and differentiation on graphene and graphene oxide. ACS Nano. 201 I;5(9):7334-734I. Copyright 20II American Chemical Society. ${ }^{52}$

biocompatibility of graphene and specifically PEG-GO. Wang et al ${ }^{44}$ evaluated the cytocompatibility of GO with human fibroblasts in vitro and in a mouse model in vivo. Fibroblasts were cultured in the presence of varying concentration of GO for up to 5 days. GO was non-toxic up to
$20 \mu \mathrm{g} / \mathrm{mL}$. Decreased cell adhesion, cell apoptosis, and lysosomal entrapment were observed at $50 \mu \mathrm{g} / \mathrm{mL}$ and higher concentration. In vivo data indicated that GO did not exhibit any observable toxicity at a dose of 0.1 and $0.25 \mathrm{mg}$. However, chronic toxicity was observed at a dose 
of $0.4 \mathrm{mg} \mathrm{GO}$ where four mice died among the group of nine animals. Lung granuloma formation was noted and GO was not cleared through the kidneys. Thus, the cytotoxicity of GO is dose and time dependent and GO can accumulate in the major organs such as lungs resulting in inflammatory response along with poor renal clearance. Therefore, GO alone may not be ideally suited for human use especially at high dosage.

Subsequently, PEG-GO was developed, and its biocompatibility was assessed for possible enhancement in compatibility over GO. Liu et al $^{11}$ demonstrated that PEGfunctionalized nano-GO (NGO-PEG) shows no obvious toxicity against HCT-116 colon cancer cells even at $500 \mathrm{mg} / \mathrm{L}$. Study of apoptosis revealed that NGO-PEG was non-toxic to MCF-7 breast cancer cells even at $100 \mathrm{mg} / \mathrm{L}$ (Figure 3A). Furthermore, studying the cellular uptake of FITC-labeled NGO-PEG by MCF-7 cells, the authors observed high uptake at $37^{\circ} \mathrm{C}$ but none at $4^{\circ} \mathrm{C}$ suggesting that NGO-PEG is internalized into the cells through energy-dependent endocytosis mechanism in a manner similar to functionalized single-walled carbon nanotubes. ${ }^{45}$ WST- 8 assay to assess cytotoxicity of PEGGO using A549 and MCF-7 cells revealed that even after $72 \mathrm{~h}$, PEG-GO did not induce toxicity up $100 \mathrm{mg} / \mathrm{L}^{10}$ (Figure 3B). PEG-GO is also reported to be cytocompatible with non-cancerous cells. Díez-Pascual et al ${ }^{46}$ developed poly(propylene fumarate)-based nanocomposite with different content of PEG-GO and demonstrated their cytocompatibility using normal human dermal fibroblasts (NHDFs). Composites with GO content of less than 2.0 wt $\%$ did not show cytotoxicity after $72 \mathrm{~h}$. At $3.0 \mathrm{wt} \% \mathrm{GO}$ content, the cell viability dropped marginally, however, at more than $85 \%$ viability, it indicated good cytocompatibility of the composites.

In vivo pharmacokinetics, long-term biodistribution, and toxicity of NGO-PEG sheets were first reported by Yang et $\mathrm{al}^{13}$ by radio-labeling with ${ }^{125} \mathrm{I}$. The pharmacokinetic data showed that the first phase half-life was 0.39 $\pm 0.097 \mathrm{~h}$ and the second phase blood circulation half-life was $6.97 \pm 0.62 \mathrm{~h}$. The volume of distribution was found to be $3.76 \pm 1.28 \mathrm{~L}$ and the area under curve $\left(\mathrm{AUC}_{0_{-}}\right)$was 4.64 $\pm 1.20 \mathrm{mg} \cdot \mathrm{min} / \mathrm{mL}$. For biodistribution study (Figure $3 \mathrm{C}$ ), ${ }^{125}$ I-NGO-PEG-treated female Balb/c mice were sacrificed at different time intervals and the organs were evaluated. The particles were initially distributed in different organs including lungs, liver, kidney, spleen, heart, stomach, intestine, and muscle, etc. but over time they were mostly accumulated in the reticuloendothelial system (RES) such as liver and spleen. Biodistribution study also indicated renal as well as fecal clearance of PEG-GO. No obvious toxicity could be found even after $20 \mathrm{mg} / \mathrm{kg}$ dose. Taken together, PEG-functionalization of GO markedly enhances its biocompatibility.

However, Luo et $\mathrm{al}^{47}$ reported contradictory observations when they studied the immunological impact of NGO-PEG. Potent cytokine responses were stimulated in peritoneal macrophages by the particles even though it was not being internalized like GO (Figure 3Da). Molecular dynamic simulations (Figure $3 \mathrm{Db}$ ) showed that NGO-PEG adsorbs onto and/or is inserted into the cell membrane, which in turn amplifies the interactions with surface receptors to result in cytokine production mediated by integrin 8-related signaling pathway. In a previous study, ${ }^{48}$ the same group found divergent biological response of macrophages when they decorated the NGO surface with PEG, bovine serum albumin (BSA) or polyethylene imine (PEI). NGO-PEG and BSA-decorated NGO were not internalized by the peritoneal macrophages and were more benign than pristine NGO. However, NGO-PEI compromised the viability of the macrophages due to electrostatic interactions with the mitochondria. In the more recent study, they report macrophage activation by NGO-PEG might decline over time. ${ }^{47}$ They stated that further in vivo experiments are warranted to test if the initial macrophage activation leads to inflammatory response. However, they proposed that NGO-PEG could be useful where immune stimulation is necessitated. As NGO-PEG elicits an immune response without producing any damage to macrophages, this might be therapeutically useful.

\section{Interaction with Stem Cells}

Stem cells are characterized by two unique attributes, their ability of self-renewal and their multi-potency, which is their ability to differentiate to several lineages. They are involved in self-repair of the human body and are widely used for tissue regeneration. ${ }^{49}$ In addition to the different types of adult stem cells and embryonic stem cells that have been identified, the more recently introduced induced pluripotent stem cells (iPSCs) can also be utilized for tissue engineering. ${ }^{50}$

Chen et $\mathrm{al}^{50}$ cultured iPSCs on glass substrates coated with graphene $(\mathrm{G})$ or GO. Cell attachment and proliferation were enhanced on GO-coated surface than on the G-coated glass. This phenomenon was attributed to the abundant oxide groups on GO that imparting hydrophilicity to the surface. ${ }^{51}$ Moreover, GO favored cell 

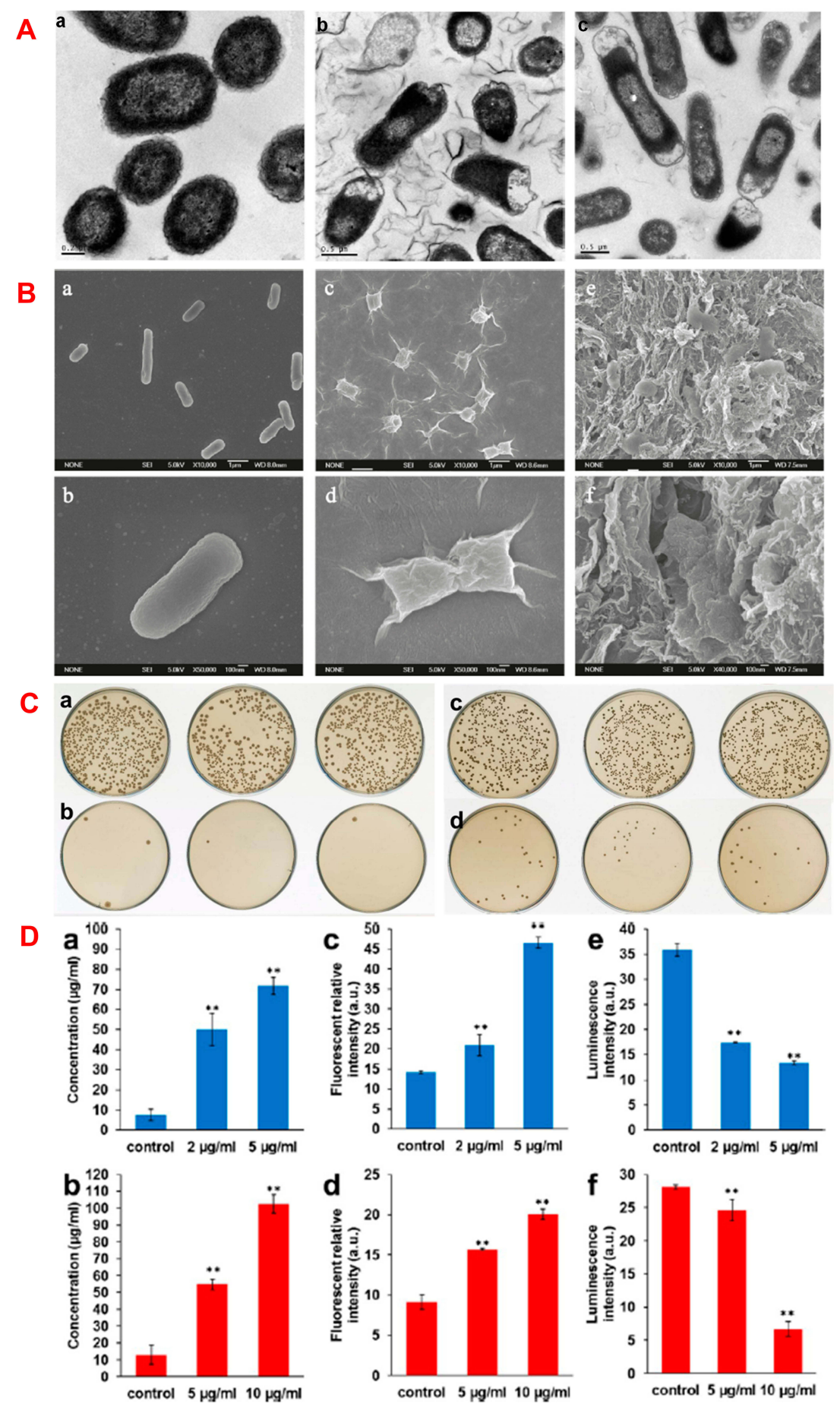

Figure 5 (A) Transmission electron microscopic (TEM) image of (a) E. coli, E. coli exposed to $85 \mu \mathrm{g} / \mathrm{ml}$ of (b) GO and (c) rGO nanosheets at $37{ }^{\circ} \mathrm{C}$ for $2 \mathrm{~h}$. Reprinted with permission from Hu W, Peng C, Luo W, et al. Graphene-based antibacterial paper. ACS Nano. 2010;4(7):4317-4323. Copyright 2010 American Chemical Society. ${ }^{60}$ (B)

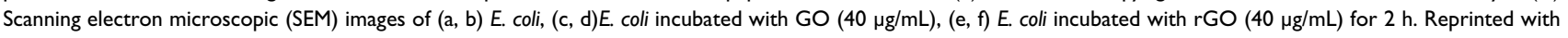
permission from Liu S, Zeng TH, Hofmann M, et al. Antibacterial activity of graphite, graphite oxide, graphene oxide, and reduced graphene oxide: membrane and oxidative stress. ACS Nano. 201 I;5(9):6971-6980. Copyright 201I American Chemical Society. ${ }^{61}$ (C) Effect of GO-PEG-Ag on bacterial colonies after 2.5 h of incubation. E. coli incubated with (a) $0 \mu \mathrm{g} / \mathrm{ml}$, (b) $5 \mu \mathrm{g} / \mathrm{ml}$ of GO-PEG-Ag. S. aureus incubated with(c) $0 \mu \mathrm{g} / \mathrm{ml}$, (d) $10 \mu \mathrm{g} / \mathrm{ml}$ of GO-PEG-Ag. Reprinted with permission from Zhao R, Lv M, Li Y, et al. Stable nanocomposite based on PEGylated and silver nanoparticles loaded graphene oxide for long-term antibacterial activity. ACS Appl Mater Interfaces. 20I7;9 (I8): 15328-1534I. Copyright 2017 American Chemical Society ${ }^{63}$ and (D) protein leakage from (a) E. coli and (b) S. aureus suspensions incubated with different GO-PEG-Ag concentrations for $2.5 \mathrm{~h}$. Effect of the different concentrations of GO-PEG-Ag on generation of cellular total ROS of (c) E. coli and (d) S. aureus incubated for I.5 h. The level of adenosine triphosphate (ATP) of (e) E. coli and (f) S. aureus incubated with different concentrations of GO-PEG-Ag for I.5 h. **P $\leq 0.0 \mathrm{I}$, GO-PEG-Ag groups compared to control group. Experiments were carried out in triplicate and standard error was determined to draw error bars. Reprinted with permission from Zhao R, Lv M, Li Y, et al. Stable nanocomposite based on PEGylated and silver nanoparticles loaded graphene oxide for long-term antibacterial activity. ACS Appl Mater Interfaces. 20I7;9(I8):I53281534I. Copyright 2017 American Chemical Society. ${ }^{63}$ 
differentiation whereas the G-coated surface helped to maintain the undifferentiated state initially. They also found differentiation to the mesoderm and ectoderm lineages on both surfaces, whereas, unlike GO, $\mathrm{G}$ suppressed endoderm differentiation Figure 5A. However, the underlying mechanism was not reported.

Lee et $\mathrm{al}^{52}$ cultured mesenchymal stem cells (MSCs) on $\mathrm{G}$ films and GO films with polydimethylsiloxane (PDMS) as the control substrate (Figure 4A). On day 1, cells on PDMS were round, whereas spindle-shaped homogenously spread cells were found on G film and large cells were observed on the GO film. Serum proteins play an important role in the adhesion and growth of cells. The highly hydrophobic PDMS surface resulted in poor cell adhesion. As GO is more hydrophilic than $\mathrm{G}$, it better adsorbed serum proteins than $\mathrm{G}^{52}$ Interestingly, the $\mathrm{G}$ film favored osteogenic differentiation rather than $\mathrm{GO}$, which was ascribed to the strong non-covalent interactions of $\mathrm{G}$ with the soluble osteogenic inducers. ${ }^{52}$ However, unlike GO, differentiation to adipocytes was suppressed on $\mathrm{G}$ films (Figure 4Ba-d) because insulin, which regulates fatty acid synthesis, denatured upon adsorption to $\mathrm{G}$ films, whereas insulin could easily interact with GO through electrostatic interactions. The size of GO nanosheets also affected stem cell differentiation. Kang et $\mathrm{al}^{53}$ demonstrated that human adiposederived MSCs (hADMSCs) on micro-sized GO (MGO)coated substrate spread much more than on the nano-GO (NGO)-coated substrate. Besides GO, the effect of PEGfunctionalized rGO (PrGO) was also evaluated on MSCs. ${ }^{54}$ PrGO was neither toxic nor impaired the differentiation potential of MSCs, which confirmed the prospect of PEGylated graphene derivatives in tissue engineering.

Aside from the larger nanosheets, GO-quantum dots (GQDs) with lateral dimensions of a few nanometers have also shown promise for promoting the differentiation of stem cells. Qiu et $\mathrm{al}^{55}$ noted that GQDs affect the pluripotency, self-renewal and differentiation of bone marrowderived MSCs. Excellent fluorescence of GQDs helped to confirm the cellular internalization by MSCs. They demonstrated that GQDs enhanced alkaline phosphatase activity and expression of several osteogenic markers in the stem cells. In a recent study, Yang et $\mathrm{al}^{56}$ studied and compared the effect of GO and GQDs on the osteogenic differentiation of human stem cells sourced from exfoliated deciduous teeth (SHEDs). The uptake of GQDs by the SHEDs and their cytoplasmic distribution were confirmed using the fluorescent property of GQDs. Interestingly, they observed that stem cell osteogenesis was augmented by GQDs but decreased when the cells were treated with GO. Some studies have been reported on the use of PEGylated GQDs for bioimaging, ${ }^{57}$ detection of metal ions, ${ }^{58}$ and cancer therapy, ${ }^{59}$ etc. However, there is little reported information on the interaction of PEGylated GQDs with stem cells. Nevertheless, given the ability of GQDs in promoting stem cell differentiation and the increased colloidal stability imparted by PEG functionalization to GO and GQDs, it is envisaged that PEGylated GQDs are an attractive candidate material for tissue engineering and should be studied further.

\section{Antibacterial Efficacy}

Antibacterial activity of GO is an attractive attribute for tissue engineering as all implants are prone to bacterial infections. Preventing infections aids tissue regeneration while enhancing patient comfort and eliminating costs of revision surgeries. $\mathrm{Hu}$ et al developed graphene-based antibacterial paper. ${ }^{60}$ They evaluated the activity of GO and rGO against $E$. coli by measuring bacterial metabolism using the Luciferase-based ATP assay. Metabolic activity decreased to $13 \%$ and $24 \%$ after $2 \mathrm{~h}$ incubation with $85 \mu \mathrm{g} / \mathrm{mL}$ of $\mathrm{GO}$ and $\mathrm{rGO}$, respectively. Colony count revealed that $E$. coli viability decreased by $98.5 \%$ and $90.0 \%$ with GO and $\mathrm{rGO}$, respectively. TEM revealed that the interaction with GO nanosheets severely damaged the cell membrane with leakage of cytoplasmic components. Similar result was observed with $\mathrm{rGO}$, although it was less efficient (Figure 5A).

Liu et $\mathrm{al}^{61}$ compared the antimicrobial potency of graphite (G), graphite oxide (GtO), GO and rGO using E. coli. GO showed highest potency for a given concentration and incubation condition, which was followed by $\mathrm{rGO}, \mathrm{Gt}$ and GtO. The loss in viability of $E$. coli was $69.3 \pm 6.1 \%$ for GO, which was almost four-folds higher than GtO. Scanning electron microscopy (SEM) revealed that the cells became flattened with loss of cellular integrity on interaction with the graphene derivatives (Figure 5B) corroborating the TEM data of $\mathrm{Hu}$ et al. ${ }^{60}$ According to Liu et al, ${ }^{61}$ aside from generating membrane stress mediated by direct physical contact, the aggregation behavior could also be important in the antibacterial potency. Carbonaceous nanomaterials exert their antibacterial activity through reactive oxygen species (ROS)-dependent generation of oxidative stress. ${ }^{62}$ To evaluate other possible causes such as ROS-independent oxidative stress, Liu et $\mathrm{al}^{61}$ studied the production of superoxide anion $\left(\mathrm{O}_{2}{ }^{-}\right)$and observed insignificant generation of superoxide anion-mediated oxidative stress. However, they found that both GO and rGO induced 


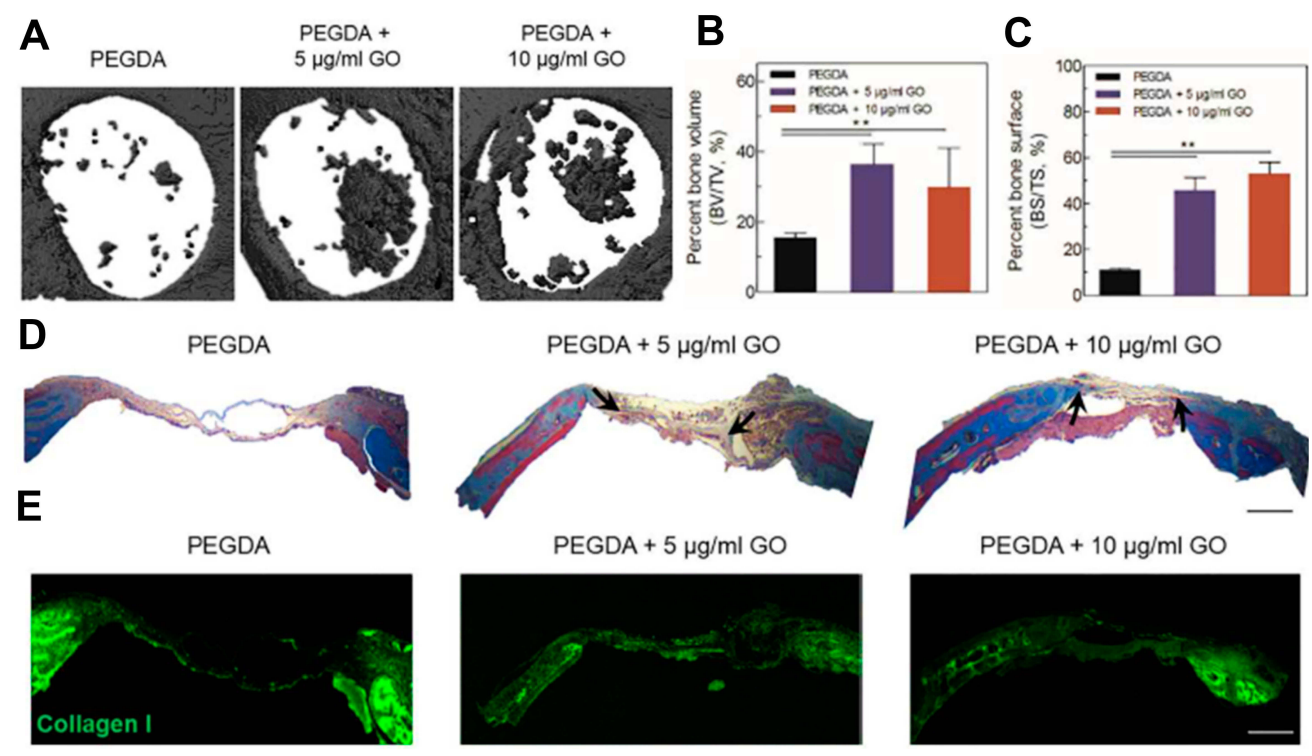

Figure 6 (A) Micro-CT image of new bone formation in mouse calvaria defect model (defect dia. $=4 \mathrm{~mm}$ ). (B) Percent bone volume and $(\mathbf{C})$ percent bone surface of PEGDA + $5 \mu \mathrm{g} / \mathrm{mL}$ GO and PEGDA + $10 \mu \mathrm{g} / \mathrm{mL}$ GO group was significantly higher than hTMSCs on PEGDA group ( $\mathrm{n}=3$, $\mathrm{P}<0.0 \mathrm{l}$ ). (D) Masson's trichrome staining for histological analysis of regenerated bone tissue (scale bar $=500 \mu \mathrm{m}$ ). (Black arrow indicated the newly deposited collagen) (E) Immunostaining was done for collagen type I in regenerated bone for each groups (scale bar $=500 \mu \mathrm{m}$ ). Reprinted with permission from Kim HD, Kim J, Koh RH, et al. Enhanced Osteogenic commitment of human Mesenchymal stem cells on polyethylene glycol based Cryogel with Graphene oxide substrate. ACS Biomater Sci Eng. 20I7;3(I0):2470-2479. Copyright 2017 American Chemical Society. ${ }^{64}$

concentration and time dependent effects on the oxidation of glutathione, which indicates superoxide anion-mediated oxidative stress produced by graphene derivatives leads to their antibacterial efficacy.

Toward addressing antimicrobial resistance, Zhao et $\mathrm{al}^{63}$ developed silver nanoparticle-loaded GO (GO-Ag) nanocomposites. GO-Ag irreversibly aggregated in physiological medium compromising their antibacterial efficacy. Thus, they synthesized PEGylated GO-Ag (GO-PEG-Ag) nanocomposite, which was stably dispersed for one month. GOPEG-Ag exhibited excellent bactericidal activity not only against gram-negative $E$. coli and gram-positive $S$. aureus (Figure 5C), but also against drug-resistant superbugs. GOPEG-Ag damaged the bacterial structure causing leakage of cytoplasmic components, decrease of metabolic activity, and the generation of ROS (Figure 5D). Recently, Workie et al ${ }^{65}$ delivered nitric oxide (NO) using fluorinated PEG@GO carrier and found more effective antibacterial activity for NO-conserved F-PEG@GO than NO-conserved GO. The hydrophobic perfluorocarbon moiety on F-PEG@GO conserved more NO than GO resulting in superior activity.

\section{Advances of PEG-GO in Tissue Engineering}

Extensive work has been conducted to develop PEG-GO as a superior carrier system for hydrophobic drugs. However, fewer studies are reported for tissue engineering. This section describes the application of PEG-GO in tissue scaffolds.

\section{Bone Tissue Engineering}

Bone disorders have steeply increased globally due to diseases and trauma of bone tissues ${ }^{66,67}$ Bone tissue grafting are widely used in the clinic to repair and replace damaged and diseased bones. Among the various grafts, autograft is considered as the gold standard. However, limited tissue availability and donor site morbidity are the major disadvantages associated with this technique. Engineered bone tissues offer a promising alternative to conventional autografts and allografts. ${ }^{68}$ Graphene and its derivatives have been widely studied for bone tissue engineering owing to their ability to promote osteogenesis of stem cells. ${ }^{69-71}$ PEG-GO has also shown promise in bone tissue engineering.

Díez-Pascual et al $^{46}$ developed PEG-GO incorporated poly (propylene fumarate) nanocomposite. Mechanical property increased in the presence of PEG-GO along with increased adhesion and growth of cells underscoring the potential of the nanocomposite for bone tissue regeneration. PEG-based hydrogels are extensively researched for stem cell culture. ${ }^{72}$ Recently, Noh et $\mathrm{al}^{73}$ prepared GO-functionalized poly(ethylene glycol) diacrylate (PEGDA) hydrogels to assess osteogenesis of human adipose derived stem cells (hADSCs). 
A major drawback of the PEGDA hydrogels as a functional tissue construct is the lack of cell adhesion sites. Cell adhesion and focal attachment improved by the incorporation of GO. The authors noted that phosphorylation of focal adhesion kinase (FAK) and downstream extracellular signal-regulated kinase (ERK) signaling were enhanced on the GO-containing hydrogels. Relative mRNA expressions of osteogenic markers such as Runt-related transcription factor 2 (RUNX2), osteopontin (OP) and bone morphogenetic protein 2 (BMP2) were significantly up-regulated in PEGDA-GO hydrogels. Intense red staining by alizarin red $\mathrm{S}$ in the PEGDA-GO hydrogel after three weeks indicated increased calcium deposition. Significantly higher expression of the protein osteocalcin (OC) was also noted in the PEGDA-GO gels. The osteogenic activity of PEGDA-GO was due to the ability of GO to activate FAK-ERK signaling pathway, which plays critical roles in osteogenesis. ${ }^{74}$

Kim et $\mathrm{al}^{64}$ prepared GO-incorporated PEGDA cryogels to evaluate the osteogenic commitment of human tonsil-derived MSCs (hTMSCs) (Figure 6). They also found PEGDA-GO improved cell attachment and activation of FAK signaling pathway. Like in the other study, osteogenic markers were upregulated and along with higher calcium deposition Osteogenesis was studied in vivo in a calvarial defect model in Balb/c-nude immunodeficient mice for up to eight weeks. $\mathrm{X}$-ray micro-computed tomography (Figure 6A) suggested 2.3-fold increase in bone volume for PEGDA-GO than the PEGDA cryogel (Figure 6B, 6C). Masson's trichrome staining indicated higher fraction of collagen matrix in PEGDAGO (Figure 6D). Collagen type I was homogeneously distributed in PEGDA cryogel incorporating $10 \mu \mathrm{g} / \mathrm{mL} \mathrm{GO}$, whereas it was limited to the scaffold surface of PEGDA (Figure 6E). Therefore, PEGDA-GO promoted osteogenesis of MSCs as well as bone tissue regeneration in vivo.

\section{Cardiac Tissue Engineering}

Since the regenerative capacity of the cardiac tissue is rather limited, diseases and disorders of the heart such as myocardial infarction, coronary artery disease, and severe cardiac ischemia cause permanent damage and loss of function. $^{24}$ Development of an engineered scaffold to mimic the cardiac tissue for modeling disease states and for use as an in vitro platform for drug screening is a challenge. A primary cause of this difficulty is that most of the biomaterials used to prepare the tissue scaffolds are non-conductive whereas the cardiac tissue is characterized by electrical conductivity of $0.005 \mathrm{~S} / \mathrm{m}$ and $0.1 \mathrm{~S} / \mathrm{m}$ in the transverse and longitudinal directions, respectively. ${ }^{24}$ Moreover, aligned submicron-sized collagen fibers provide the mechanical properties of the tissue. Few reports indicate that substrates with anisotropic topography are effective in mimicking the ultrastructure and orientations of cardiac tissue fibers. ${ }^{75-78}$ Controlling the conductivity of the substrate affects the phenotype in vitro. ${ }^{8,79}$ However, the developing substrates exhibiting combination of physiologicallyrelevant conductivity and topography remains challenging. Smith et $\mathrm{al}^{84}$ developed micro- and nano-patterned GO-PEG hybrid scaffold and neonatal rat ventricular myocytes (NRVMs) were cultured for seven days. Additionally, to examine the effect of substrate conductivity on cardiac cells, cells were cultured on PEG, GOPEG and oxygen plasma-treated graphene-PEG (PEG. OG) with increased conductivity. Cells were immunostained for $\alpha$-actinin, a sarcomeric protein present on the $\mathrm{Z}$ line and $\mathrm{CX} 43$, a gap-junction protein necessary for electrical coupling of cardiac cells. No significant differences were observed in cellular alignment suggesting that cracks and/or ridges of graphene in the grooves were too narrow for cell adhesion. CX43 expression suggested the development of preliminary gap-junction between the cells. Sarcomere length for the cells grown on the PEG substrate was found to be $1.69 \pm 0.13 \mu \mathrm{m}$, whereas, increased sarcomere length of $1.97 \pm 0.08 \mu \mathrm{m}$ and 1.98 $\pm 0.06 \mu \mathrm{m}$ could be observed for GO-PEG and PEG.OG, respectively. Wider Z-band is indicative of a more mature muscle and it was highest for cells on PEG.OG. The expression of CX43 and SERCA2 which regulate the electrophysiological activity of cardiac tissues increased on PEG.OG compared to the PEG substrate. These data demonstrate GO-PEG hybrid facilitates the growth of cardiac cells through topography and electrical conductivity. The electrical conductivity of PEG-GO-based polymer composites was reported in a recent study. ${ }^{80}$ PEG grafted graphene nanosheets (PEG-g-GN) were uniformly dispersed in polylactic acid (PLA). The composite exhibited tensile strength of $59.46 \mathrm{MPa}$ with conductivity of $9.69 \pm 10^{-4} \mathrm{~S} \mathrm{~cm}^{-1}$.

\section{Skin Tissue Engineering}

Engineered skin is in great demand for treating various clinical conditions but is particularly challenging for diabetic wounds. ${ }^{85}$ Chu et al recently developed GO-PEG-mediated quercetin-modified acellular dermal matrix (ADM-GO-PEG /Que) hybrid scaffolds for healing of diabetic wounds. ${ }^{85}$ They used ADM to prepare the scaffold, as it is a naturally- 
derived ECM with inherent biocompatibility, adequate mechanical property, and biodegradability, etc. ${ }^{81}$ ADMs have 3D nanofibrous architecture used for the targeted delivery of MSCs in full-thickness cutaneous tissue defects. ${ }^{82}$ Diabetes was induced by intraperitoneal injection of streptozocin (STZ) daily for 5 days. A circular defect $(7 \mathrm{~mm}$ diameter) was punched on the dorsum. Wounded diabetic animals were divided into four groups: control, ADM, ADM-GO/Que and ADM-GO-PEG/Que hybrid scaffold. At Day 7, the control animals showed severe inflammatory response and incomplete healing after Day 21. The animals treated with the ADM-GO-PEG/Que hybrid scaffolds showed better wound closure at $87.34 \pm 2.6 \%$ on Day 21 with no hypertrophic scar. Masson's trichome staining showed collagen deposition and neovascularization in the lower epidermis. Collagen regeneration, neovascularization and skin appendage regeneration was enhanced for ADMGO-PEG/Que treated group. Hair follicles and mature vessels were observed in the dermis of ADM-GO-PEG/Quetreated animals at Day 14. Additionally, angiogenesis is also important in chronic wound healing. RT-PCR and Western blot results for Collagen type I and III, and $\alpha$-smooth muscle actin ( $\alpha$-SMA) expression confirmed healing and neovasculature demonstrating the efficacy of ADM-GO-PEG/Que hybrid scaffolds in healing of diabetic wounds.

\section{Neural Tissue Engineering}

Unique electrical and chemical properties of graphenebased nanomaterial are beneficial for neural tissue regeneration. $\mathrm{Li}$ et $\mathrm{al}^{83}$ demonstrated that unmodified graphene can facilitate neuronal growth. Compared with tissue culture polystyrene surfaces, the average length and number of neurites were enhanced significantly on graphene after 2 to 7 days of cell seeding. Moreover, the significant enhancement of growth associated protein-43 (GAP-43) for cells on graphene suggested the efficiency of graphene as a substrate for neurite sprouting and outgrowth. A recent report suggested the influence of the surface charge of GO on neuronal branching and outgrowth. ${ }^{86}$ In this study, surface functionalization of GO was done to develop neutral, zwitterionic, negatively-charged GO and positivelycharged GO. Notably, positively-charged GO was prepared by the functionalization of $\mathrm{GO}$ with amineterminated PEG. Ninety-six percent viability was observed for primary hippocampal neuronal cells derived from postnatal Sprague-Dawley rat pups after seven days of culture for all of the functionalized $\mathrm{GO}$ substrates confirming cytocompatibility. However, total outgrowth and the maximum neurite length per neuron were longer for neurons on positively-charged GO substrate. The cell body area per neuron and branching of neurites were also significantly higher for the positivelycharged GO substrate. Additionally, immunostaining also confirmed that the positively-charged GO substrate was beneficial for neurite outgrowth and branching.

\section{Summary and Future Prospects}

Graphene and its derivatives have shown promise in biomedical applications. GO sheets can be prepared by oxidation of graphite. GO possess tunable functional groups, which can be easily functionalized further for a variety of applications. Cytotoxicity at large dosages and prolonged exposure of GO limits its clinical translation. PEG-functionalization can overcome many of the limitations of GO. PEG-GO exhibits excellent aqueous solubility and stability in bodily fluids. PEG-GO has been shown to be non-toxic unlike its pristine counterpart. Studies in vivo reveal the biodistribution of PEG-GO to major organs initially followed by renal and fecal clearance. Antibacterial efficacy of PEG-GO was reported against both gram-negative and gram-positive bacteria, which can impart resistance to implant-associated infections. Few studies have been reported on the use of PEG-GO in composite materials to prepare scaffolds for tissue engineering. However, these scaffolds incorporating PEG-GO for bone, cardiac, skin, and neural tissue engineering reveal promising outcomes.

Despite its early promise, more dedicated efforts are required to develop technologies suited for clinical translation using PEG-functionalized GO. With the emergence of three-dimensional (3D) printing, scaffolds can be engineered that better mimic the ECM. PEG can be functionalized with different end groups so as to impart unique functionality to the nanoparticles when conjugated to GO. PEG containing acrylate groups could be incorporated in photo-curable bioinks for $3 \mathrm{D}$ printing of tissue scaffolds. Long-term effects of implanting scaffolds incorporating PEG-GO for tissue regeneration are poorly understood. More in vivo studies are warranted to fully understand the effect on the regenerated tissue, biodistribution, and systemic accumulation and clearance. In summary, PEG-GO is poised to emerge as a choice of biomaterial for advanced tissue engineering applications. 


\section{Acknowledgments}

Authors thank the Nanomission Program of the Department of Science and Technology, Govt. of India for funding (DST/ NM/NB/2018/119(G)). S.G. is supported by the National Postdoctoral Fellowship of the Science and Engineering Research Board (SERB), Govt. of India (PDF/2019/000553).

\section{Disclosure}

The authors declare no conflicts of interest in this work.

\section{References}

1. Novoselov KS, Geim AK, Morozov SV, et al. Electric field effect in atomically thin carbon films. Science. 2004;306(5696):666-669. doi:10.1126/science.1102896

2. Ranjbartoreh AR, Wang B, Shen X, Wang G. Advanced mechanical properties of graphene paper. J Appl Phys. 2011;109(1):014306. doi:10.1063/1.3528213

3. Wu ZS, Ren W, Gao L, et al. Synthesis of graphene sheets with high electrical conductivity and good thermal stability by hydrogen arc discharge exfoliation. ACS Nano. 2009;3(2):411-417. doi:10.1021/nn900020u

4. Novoselov KS, Geim AK. The rise of graphene. Nat Mater. 2007;6 (3):183-191. doi:10.1038/nmat1849

5. Bhuyan MSA, Uddin MN, Islam MM, Bipasha FA, Hossain SS. Synthesis of graphene. Int Nano Lett. 2016;6:65-83. doi:10.1007/ s40089-015-0176-1

6. Kumar S, Chatterjee K. Comprehensive review on the use of graphene-based substrates for regenerative medicine and biomedical devices. ACS Appl Mater Interfaces. 2016;8(40):26431-26457. doi:10.1021/acsami.6b09801

7. Priyadarsini S, Mohanty S, Mukherjee S, Basu S, Mishra M. Graphene and graphene oxide as nanomaterials for medicine and biology application. J Nanostruct Chem. 2018;8(2):123-137. doi:10.1007/s40097-018-0265-6

8. Shin SR, Zihlmann C, Akbari M, et al. Reduced graphene oxide-gelMA hybrid hydrogels as scaffolds for cardiac tissue engineering. Small. 2016;12(27):3677-3689. doi:10.1002/smll.201600178

9. Chen D, Feng H, Li J. Graphene oxide: preparation, functionalization, and electrochemical applications. Chem Rev. 2012;112 (11):6027-6053. doi:10.1021/cr3000412

10. Xu Z, Wang S, Li Y, Wang M, Shi P, Huang X. Covalent functionalization of graphene oxide with biocompatible poly (ethylene glycol) for delivery of paclitaxel. ACS Appl Mater Interfaces. 2014;6 (19):17268-17276. doi:10.1021/am505308f

11. Liu Z, Robinson JT, Sun X, Dai H. PEGylated nanographene oxide for delivery of water-insoluble cancer drugs. $J$ Am Chem Soc. 2008;130(33):10876-10877. doi:10.1021/ja803688x

12. Kazempour M, Namazi H, Akbarzadeh A, Kabiri R. Synthesis and characterization of PEG-functionalized graphene oxide as an effective pH-sensitive drug carrier. Artif Cells Nanomed Biotechnol. 2019;47(1):90-94. doi:10.1080/21691401.2018.1543196

13. Yang K, Wan J, Zhang S, Zhang Y, Lee ST, Liu Z. In vivo pharmacokinetics, long-term biodistribution, and toxicology of PEGylated graphene in mice. ACS Nano. 2011;5(1):516-522. doi:10.1021/nn1024303

14. Tian B, Wang C, Zhang S, Feng L, Liu Z. Photothermally enhanced photodynamic therapy delivered by nano-graphene oxide. ACS Nano. 2011;5(9):7000-7009. doi:10.1021/nn201560b

15. Zhang W, Guo Z, Huang D, Liu Z, Guo X, Zhong H. Synergistic effect of chemo-photothermal therapy using PEGylated graphene oxide. Biomaterials. 2011;32(33):8555-8561. doi:10.1016/j.biomaterials.2011.07.071

16. Langer R, Vacanti JP. Tissue engineering. Science. 1993;260 (5110):920-926. doi:10.1126/science.8493529
17. Bunnell BA, O'Donnell BT, Ives CJ. Beyond the present constraints that prevent a wide spread of tissue engineering and regenerative medicine approaches. Front Bioeng Biotechnol. 2019;7:95. doi: $10.3389 /$ fbioe. 2019.00095

18. Williams DF. Challenges with the development of biomaterials for sustainable tissue engineering. Front Bioeng Biotechnol. 2019;7:127. doi:10.3389/fbioe.2019.00127

19. Shahrousvand M, Ghollasi M, Zarchi AA, Salimi A. Osteogenic differentiation of hMSCs on semi-interpenetrating polymer networks of polyurethane/poly (2-hydroxyethyl methacrylate)/cellulose nanowhisker scaffolds. Int J Biol Macromol. 2019;138:262-271. doi:10. 1016/j.ijbiomac.2019.07.080

20. Prasadh S, Suresh S, Wong R. Osteogenic potential of graphene in bone tissue engineering scaffolds. Materials. 2018;11(8):1430. doi: $10.3390 / \mathrm{ma} 11081430$

21. Shamekhi MA, Mirzadeh H, Mahdavi H, Rabiee A, MohebbiKalhori D, Eslaminejad MB. Graphene oxide containing chitosan scaffolds for cartilage tissue engineering. Int $J$ Biol Macromol. 2019;127:396-405. doi:10.1016/j.ijbiomac.2019.01.020

22. Jiang L, Chen D, Wang $Z$, et al. Preparation of an electrically conductive graphene oxide/chitosan scaffold for cardiac tissue engineering. Appl Biochem Biotechnol. 2019;188(4):952-964. doi:10. 1007/s12010-019-02967-6

23. Bei HP, Yang Y, Zhang Q, et al. Graphene-based nanocomposites for neural tissue engineering. Molecules. 2019;24(4):658. doi:10.3390/ molecules 24040658

24. Ghosal K, Sarkar K. Biomedical applications of graphene nanomaterials and beyond. ACS Biomater Sci Eng. 2018;4(8):2653-2703. doi:10.1021/acsbiomaterials.8b00376

25. Yang Y, Asiri AM, Tang Z, Du D, Lin Y. Graphene based materials for biomedical applications. Mater Today. 2013;16(10):365-373. doi:10.1016/j.mattod.2013.09.004

26. Shin SR, Li YC, Jang HL, et al. Graphene-based materials for tissue engineering. Adv Drug Delivery Rev. 2016;105:255-274. doi:10.10 16/j.addr.2016.03.007

27. Brodie B. Sur le poidsatomique du graphite. Ann Chim Phys. 1860;59 (466): 472.

28. Staudenmaier L. Verfahrenzurdarstellung der graphitsäure. Eur J Inorg Chem. 1899;32(2):1394-1399.

29. Hummers WS Jr, Offeman RE. Preparation of graphitic oxide. $J$ Am Chem Soc. 1958;80(6):1339. doi:10.1021/ja01539a017

30. Marcano DC, Kosynkin DV, Berlin JM, et al. Improved synthesis of graphene oxide. ACS Nano. 2010;4(8):4806-4814. doi:10.1021/ $\mathrm{nn} 1006368$

31. Koch KR. Oxidation by Mn207: an impressive demonstration of the powerful oxidizing property of dimanganeseheptoxide. J Chem Educ. 1982;59(11):973. doi:10.1021/ed059p973.3

32. Salavagione HJ, Gomez MA, Martinez G. Polymeric modification of graphene through esterification of graphite oxide and poly (vinyl alcohol). Macromolecules. 2009;42(17):6331-6334. doi:10.1021/ ma900845w

33. Li Y, Gao W, Ci L, Wang C, Ajayan PM. Catalytic performance of $\mathrm{Pt}$ nanoparticles on reduced graphene oxide for methanol electro-oxidation. Carbon. 2010;48(4):1124-1130. doi:10.1007/ s12274-008-8021-8

34. Shan C, Yang H, Han D, Zhang Q, Ivaska A, Niu L. Watersoluble graphene covalently functionalized by biocompatible poly-L-lysine. Langmuir. 2009;25(20):12030-12033. doi:10.10 21/la903265p

35. Wang G, Shen X, Wang B, Yao J, Park J. Synthesis and characterisation of hydrophilic and organophilic graphene nanosheets. Carbon. 2009;47(5):1359-1364. doi:10.1016/j.carbon.2009.01.027

36. Zhang S, Xiong P, Yang X, Wang X. Novel PEG functionalized graphene nanosheets: enhancement of dispersibility and thermal stability. Nanoscale. 2011;3(5):2169-2174. doi:10.1039/ C0NR00923G 
37. Park YJ, Park SY, In I. Preparation of water soluble graphene using polyethylene glycol: comparison of covalent approach and noncovalent approach. J Ind Eng Chem. 2011;17(2):298-303. doi:10.1016/j. jiec.2011.02.027

38. Zhang J, Xu Y, Cui L, et al. Mechanical properties of graphene films enhanced by homo-telechelic functionalized polymer fillers via $\pi-\pi$ stacking interactions. Compos Part A Appl Sci Manuf. 2015;71:1-8. doi:10.1016/j.compositesa.2014.12.013

39. Kumar S, Parekh SH. Linking graphene-based material physicochemical properties with molecular adsorption, structure and cell fate. Commun Chem. 2020;3(1):1. doi:10.1038/s42004-0190254-9

40. Chong Y, Ge C, Yang Z, et al. Reduced cytotoxicity of graphene nanosheets mediated by blood-protein coating. ACS Nano. 2015;9 (6):5713-5724. doi:10.1021/nn5066606

41. Baweja L, Balamurugan K, Subramanian V, Dhawan A. Effect of graphene oxide on the conformational transitions of amyloid beta peptide: A molecular dynamics simulation study. J Mol Graph Model. 2015;61:175-185. doi:10.1016/j.jmgm.2015.07.007

42. Vovusha H, Banerjee D, Yadav MK, et al. Binding characteristics of anticancer drug doxorubicin with two-dimensional graphene and graphene oxide: insights from density functional theory calculations and fluorescence spectroscopy. $J$ Phys Chem C. 2018;122 (36):21031-21038. doi:10.1021/acs.jpcc.8b04496

43. Mahdavi M, Fattahi A, Tajkhorshid E, Nouranian S. Molecular insights into the loading and dynamics of doxorubicin on PEGylated graphene oxide nanocarriers. ACS Appl Bio Mater. 2020;3(3):1354-1363. doi:10.1021/acsabm.9b00956

44. Wang K, Ruan J, Song H, et al. Biocompatibility of graphene oxide. Nanoscale Res Lett. 2011;6(8). doi:10.1007/s11671-010-9751-6

45. Kam NWS, Liu Z, Dai H. Carbon nanotubes as intracellular transporters for proteins and DNA: an investigation of the uptake mechanism and pathway. Angew Chem Int Ed. 2006;45(4):577-581. doi:10.1002/anie.200503389

46. Díez-Pascual AM, Diez-Vicente AL. Poly (propylene fumarate)/polyethylene glycol-modified graphene oxide nanocomposites for tissue engineering. ACS Appl Mater Interfaces. 2016;8(28):17902-17914. doi:10.1021/acsami.6b05635

47. Luo N, Weber JK, Wang S, et al. PEGylated graphene oxide elicits strong immunological responses despite surface passivation. Nat Commun. 2017;8(1):1. doi:10.1038/ncomms14537

48. Luo N, Ni D, Yue H, Wei W, Ma G. Surface-engineered graphene navigate divergent biological outcomes toward macrophages. ACS Appl Mater Interfaces. 2015;7(9):5239-5247. doi:10.1021/am5084607

49. Lee WC, Loh KP, Lim CT. When stem cells meet graphene: opportunities and challenges in regenerative medicine. Biomaterials. 2018;155:236-250. doi:10.1016/j.biomaterials.2017.10.004

50. Chen GY, Pang DP, Hwang SM, Tuan HY, Hu YC. A graphene-based platform for induced pluripotent stem cells culture and differentiation. Biomaterials. 2012;33(2):418-427. doi:10.1016/j. biomaterials.2011.09.071

51. Liu Q, Shi J, Sun J, Wang T, Zeng L, Jiang G. Graphene and graphene oxide sheets supported on silica as versatile and highperformance adsorbents for solid-phase extraction. Angew Chem Int Ed. 2011;50(26):5913-5917. doi:10.1002/anie.201007138

52. Lee WC, Lim CH, Shi H, et al. Origin of enhanced stem cell growth and differentiation on graphene and graphene oxide. ACS Nano. 2011;5(9):7334-7341. doi:10.1021/nn202190c

53. Kang ES, Song I, Kim DS, et al. Size-dependent effects of graphene oxide on the osteogenesis of human adipose-derived mesenchymal stem cells. Colloids Surf B. 2018;169:20-29. doi:10.1016/j. colsurfb.2018.04.053

54. Syama S, Aby CP, Maekawa T, Sakthikumar D, Mohanan PV. Nano-bio compatibility of PEGylated reduced graphene oxide on mesenchymal stem cells. 2D Mater. 2017;4(2):025066. doi:10.1088/ 2053-1583/aa65c2
55. Qiu J, Li D, Mou X, et al. Effects of graphene quantum dots on the self-renewal and differentiation of mesenchymal stem cells. Adv Healthc Mater. 2016;5(6):702-710. doi:10.1002/ adhm.201500770

56. Yang X, Zhao Q, Chen Y, et al. Effects of graphene oxide and graphene oxide quantum dots on the osteogenic differentiation of stem cells from human exfoliated deciduous teeth. Artif Cells Nanomed Biotechnol. 2019;47(1):822-832. doi:10.1080/21691401.2019.1576706

57. Wang KQ, Li KR, Yu B, Shen YQ, Cong HL. Application of PEGylated graphene quantum dots in cell imaging. Ferroelectrics. 2019;547(1):21-26. doi:10.1080/00150193.2019.1592479

58. Lou Y, Ji J, Qin A, et al. Cane molasses graphene quantum dots passivated by PEG functionalization for detection of metal ions. ACS Omega. 2020;5(12):6763-6772. doi:10.1021/acsomega.0c00098

59. Ko NR, Van SY, Hong SH, et al. Dual pH-and GSH-responsive degradable PEGylated graphene quantum dot-based nanoparticles for enhanced HER2-positive breast cancer therapy. Nanomaterials. 2020;10(1):91. doi:10.3390/nano10010091

60. $\mathrm{Hu} \mathrm{W}$, Peng $\mathrm{C}$, Luo W, et al. Graphene-based antibacterial paper. ACS Nano. 2010;4(7):4317-4323. doi:10.1021/nn101097v

61. Liu S, Zeng TH, Hofmann M, et al. Antibacterial activity of graphite, graphite oxide, graphene oxide, and reduced graphene oxide: membrane and oxidative stress. ACS Nano. 2011;5(9):6971-6980. doi: $10.1021 / \mathrm{nn} 202451 \mathrm{x}$

62. Gurunathan S, Han JW, Dayem AA, Eppakayala V, Kim JH. Oxidative stress-mediated antibacterial activity of graphene oxide and reduced graphene oxide in Pseudomonas aeruginosa. Int $J$ Nanomed. 2012;7:5901-5914. doi:10.2147/IJN.S37397

63. Zhao R, Lv M, Li Y, et al. Stable nanocomposite based on PEGylated and silver nanoparticles loaded graphene oxide for long-term antibacterial activity. ACS Appl Mater Interfaces. 2017;9(18):15328-15341. doi:10.1021/acsami.7b03987

64. Kim HD, Kim J, Koh RH, et al. Enhanced Osteogenic commitment of human Mesenchymal stem cells on polyethylene glycol-based Cryogel with Graphene oxide substrate. ACS Biomater Sci Eng. 2017;3(10):2470-2479. doi:10.1021/acsbiomaterials.7b00299

65. Workie YA, Sabrina IT, Krafft MP. Nitric oxide gas delivery by fluorinated poly (Ethylene Glycol)@ graphene oxide carrier toward pharmacotherapeutics. ACS BiomaterSci Eng. 2019;5(6):2926-2934. doi:10.1021/acsbiomaterials.9b00474

66. iofbonehealth.org [Website on the internet]. Washington, D.C., USA: Inernational Osteoporosis Foundation. Available from: https://www.iofbo nehealth.org/facts-statistics. Accessed June 24, 2020.

67. Office of the Surgeon General (US). Bone Health and Osteoporosis: A Report of the Surgeon General. Rockville (MD): Office of the Surgeon General (US); 2004:4. The Frequency of Bone Disease.

68. Yaszemski MJ, Payne RG, Hayes WC, Langer R, Mikos AG. Evolution of bone transplantation: molecular, cellular and tissue strategies to engineer human bone. Biomaterials. 1996;17 (2):175-185. doi:10.1016/0142-9612(96)85762-0

69. Shadjou N, Hasanzadeh M. Graphene and its nanostructure derivatives for use in bone tissue engineering: recent advances. J Biomed Mater Res Part A. 2016;104(5):1250-1275. doi:10.1002/jbm.a.35645

70. Dubey N, Bentini R, Islam I, Cao T, Castro Neto AH, Rosa V. Graphene: a versatile carbon-based material for bone tissue engineering. Stem Cells Int. 2015;2015:1-12. doi:10.1155/2015/804213

71. Kang ES, Kim DS, Suhito IR, et al. Guiding osteogenesis of mesenchymal stem cells using carbon-based nanomaterials. Nano Converg. 2017;4(1):2. doi:10.1186/s40580-017-0096-z

72. Whitehead AK, Barnett HH, Caldorera-Moore ME, Newman JJ. Poly (ethylene glycol) hydrogel elasticity influences human mesenchymal stem cell behavior. Regener Biomater. 2018;5(3):167-175. doi:10. 1093/rb/rby008

73. Noh M, Kim SH, Kim J, et al. Graphene oxide reinforced hydrogels for osteogenic differentiation of human adipose-derived stem cells RSC Adv. 2017;7(34):20779-20788. doi:10.1039/c7ra02410j 
74. Salasznyk RM, Klees RF, Williams WA, Boskey A, Plopper GE. Focal adhesion kinase signaling pathways regulate the osteogenic differentiation of human mesenchymal stem cells. Exp Cell Res. 2007;313(1):22-37. doi:10.1016/j.yexcr.2006.09.013

75. Ghosh LD, Ravi V, Jain A, Panicker AG, Sundaresan NR, Chatterjee K. Sirtuin 6 mediated stem cell cardiomyogenesis on protein coated nanofibrous scaffolds. Nanomedicine. 2019;19:145-155. doi:10.1016/j.nano.2019.03.005

76. Jain A, Hasan J, Desingu PA, Sundaresan NR, Chatterjee K. Engineering an in vitro organotypic model for studying cardiac hypertrophy. Colloids Surf B. 2018;165:355-362. doi:10.1016/j. colsurfb.2018.02.036

77. Carson D, Hnilova M, Yang X, et al. Nanotopography-induced structural anisotropy and sarcomere development in human cardiomyocytes derived from induced pluripotent stem cells. ACS Appl Mater Interfaces. 2016;8 (34):21923-21932. doi:10.1021/acsami.5b11671

78. Kim DH, Lipke EA, Kim P, et al. Nanoscale cues regulate the structure and function of macroscopic cardiac tissue constructs. Proc Natl Acad Sci. 2010;107(2):565-570. doi:10.1073/pnas.0906504107

79. Shevach M, Fleischer S, Shapira A, Dvir T. Gold nanoparticle-decellularized matrix hybrids for cardiac tissue engineering. Nano Lett. 2014;14(10):5792-5796. doi:10.1021/nl502673m

80. Huang K, Yu H, Xie M, Liu S, Wu F. Effects of poly (ethylene glycol)-grafted graphene on the electrical properties of poly (lactic acid) nanocomposites. RSC $A d v$. 2019;9(19):10599-10605. doi:10. 1039/c9ra01060b
81. Xing Q, Vogt C, Leong KW, Zhao F. Highly aligned nanofibrous scaffold derived from decellularized human fibroblasts. Adv Funct Mater. 2014;24(20):3027-3035. doi:10.1002/adfm.201303460

82. Wang Q, Jin Y, Deng X, et al. Second-harmonic generation microscopy for assessment of mesenchymal stem cell-seeded acellular dermal matrix in wound-healing. Biomaterials. 2015;53:659-668. doi:10.1016/j.biomaterials.2015.03.011

83. Li N, Zhang X, Song Q, et al. The promotion of neurite sprouting and outgrowth of mouse hippocampal cells in culture by graphene substrates. Biomaterials. 2011;32(35):9374-9382. doi:10.1016/j. biomaterials.2011.08.065

84. Smith AS, Yoo H, Yi H, et al. Micro-and nano-patterned conductive graphene-PEG hybrid scaffolds for cardiac tissue engineering. Chem Commun. 2017;53(53):7412-7415. doi:10.1039/c7cc01988b

85. Chu J, Shi P, Yan W, et al. PEGylated graphene oxide-mediated quercetin-modified collagen hybrid scaffold for enhancement of MSCs differentiation potential and diabetic wound healing. Nanoscale. 2018;10(20):9547-9560. doi:10.1039/C8NR02538J

86. Tu Q, Pang L, Chen Y, et al. Effects of surface charges of graphene oxide on neuronal outgrowth and branching. Analyst. 2014;139 (1):105-115. doi:10.1039/c3an01796f
International Journal of Nanomedicine

\section{Publish your work in this journal}

The International Journal of Nanomedicine is an international, peerreviewed journal focusing on the application of nanotechnology in diagnostics, therapeutics, and drug delivery systems throughout the biomedical field. This journal is indexed on PubMed Central, MedLine, CAS, SciSearch ${ }^{\mathbb{}}$, Current Contents ${ }^{\mathbb{R}} /$ Clinical Medicine,

\section{Dovepress}

Journal Citation Reports/Science Edition, EMBase, Scopus and the Elsevier Bibliographic databases. The manuscript management system is completely online and includes a very quick and fair peer-review system, which is all easy to use. Visit http://www.dovepress.com/ testimonials.php to read real quotes from published authors. 